\title{
Diel Vertical Distribution of Zooplankton in a Tropical Reservoir on New Moon and Full Moon Days
}

\author{
Walisundara W.M.T.M., Jayasinghe A.* and Asanthi H.B. \\ University of Ruhuna, Sri Lanka \\ *uasankadj@yahoo.com
}

\begin{abstract}
Diel vertical migration of zooplankton is a well documented phenomenon, however the dynamics in vertical distribution due to changing moonlight intensity is still in debate. This study compares the diel vertical distribution of zooplankton in full moon and new moon days in Lunugamwehera reservoir. Samples of zooplankton were collected from 3 depth levels (surface, $3 \mathrm{~m}$ and $6 \mathrm{~m}$ ) at six-hour time intervals (noon, dusk, midnight and dawn) from three sites of the reservoir. Sampling was carried out on new moon and full moon days from August to November, 2015. Zooplankton abundance (individuals $\mathrm{L}^{-1}$ ) at different depths was determined by direct counting under light microscope. Physico-chemical parameters (temperature, $\mathrm{pH}$, and dissolved oxygen) were measured at each depth level. Average water depth was measured at each site. Also, at each site, surface light intensity was measured using a portable Lux meter. Average light intensity in full moon nights was $0.0042 \mathrm{Wm}^{-2}$, while that was $0.0000 \mathrm{Wm}^{-2}$ in new moon nights. On new moon days, the noon and midnight total zooplankton abundances in surface layer were significantly different (Mann-Whitney Wilcoxon; $\mathrm{P}<0.05)$. Rotifera was the most diverse group identified, and contained 12 species. Copepods and cladocerans were dominant at the bottom layer in the noon, and at the middle layer in the dusk. When taxonomic group-wise considered, only copepods showed significant differences in abundance among the three depth layers $(\mathrm{P}<0.05$; One-way ANOVA) on both full and new moon days. Cluster analysis on diversity, divided new moon and full moon samples clearly into 2 separate clusters except that all ostracods appeared in new moon cluster and all cladocerans appeared in full moon cluster. Separate correspondence analyses (CA) for day and night samples showed that the vertical distribution of Rotifera was different from other taxonomic groups on both full and new moon days. Significant positive correlation between zooplankton density and DO $(r=0.835, \mathrm{P}=0.01)$ and significant negative correlation between zooplankton abundance and water temperature on new moon day $(\mathrm{r}=-0.690 \mathrm{P}<0.05)$ were observed. Results clearly showed significant differences between day and night samples on new moon days. However, when individual taxonomic groups were considerd, except cladocerans, others did not show any corelation with the light intensity on new moon days.
\end{abstract}

Keywords: Vertical migration, Zooplankton, Lunar cycle, Moonlight intensity, Lunugamwehera reservoir

Proceedings of the International Forestry and Environment Symposium 2016, Department of Forestry and Environmental Science, University of Sri Jayewardenepura, Sri Lanka. 